\title{
Erratum to: Advances in Human Factors in Training, Education, and Learning Sciences
}

Salman Nazir, Anna-Maria Teperi, and Aleksandra Polak-Sopińska

\section{Erratum to: \\ S. Nazir et al. (Eds.): Advances in Human Factors in Training, Education, and Learning Sciences, AISC 785, https://doi.org/10.1007/978-3-319-93882-0}

In the original version of the book, the following belated corrections have been incorporated:

Author name "Wally Smith" should be included in chapter "Challenges in Creating a Mobile Digital Tutor for Clinical Communications Training".

Affiliation of editor "Aleksandra Polak-Sopinska" should be changed as "Department of Production Management and Logistics, Faculty of Management and Production Engineering" in Frontmatter and chapter "Challenges for Logistics Education in Industry 4.0 "'.

The correction book has been updated with the changes.

The updated online version of this book can be found at https://doi.org/10.1007/978-3-319-93882-0

https://doi.org/10.1007/978-3-319-93882-0_24

https://doi.org/10.1007/978-3-319-93882-0_32 